J. Lake Sci. (湖泊科学), 2014, 26(6): 931-938

http://www. jlakes. org. E-mail : jlakes@niglas.ac.cn

(C) 2014 by Journal of Lake Sciences

\title{
乌梁素海大气重金属沉降入湖通量初步估算"
}

\author{
尹琳琳 $^{1,2}$, 贾克力 ${ }^{1 * *}$, 史小红 ${ }^{1}$, 赵胜男 ${ }^{1}$, 杨 芳 $^{1}$, 吴 用 $^{1}$ \\ $(1:$ 内蒙古农业大学, 呼和浩特 010018$)$ \\ $(2$ : 内蒙古自治区水土保持监测站, 呼和浩特 010019)
}

\begin{abstract}
摘 要: 重金属元素以大气颗粒物为载体, 最终以沉降的方式进入湖泊水体, 会引起湖泊的重金属污染. 为调查大气沉降 对乌梁素海重金属污染的贡献,于 2013 年 7 月 1 日至 30 日围绕乌梁素海进行大气沉降样品采集, 分别测定 $\mathrm{Cu} 、 \mathrm{Zn} 、 \mathrm{~Pb} 、$ $\mathrm{Cd} 、 \mathrm{Cr} 、 \mathrm{Hg} 、 \mathrm{As} 7$ 种重金属元素的含量,并在此基础上估算 7 月大气重金属沉降通量及人湖量. 结果表明,乌梁素海重金属 元素大气沉降通量大小依次为: $\mathrm{Zn}>\mathrm{Pb}>\mathrm{Cu}>\mathrm{Cr}>\mathrm{As}>\mathrm{Hg}>\mathrm{Cd}$. 结合社会调查情况及数据分析显示, 大气微粒携带重金 属借助风力迁移, 较大的沉降通量出现在主风向的下风向区域,说明风向是影响乌梁素海大气重金属沉降通量的主要因 素之一. 排干输人与大气沉降方式下的乌梁素海重金属人湖量比较发现,大气沉降是除排干输人外湖泊的另一重要重金 属污染源. $\mathrm{Zn} 、 \mathrm{~Pb} 、 \mathrm{Cu} 、 \mathrm{Cr} 、 \mathrm{As} 、 \mathrm{Hg} 、 \mathrm{Cd}$ 等重金属元素月人湖量分别为 $10.6 、 1.04 、 1.02 、 0.833 、 0.342 、 0.00514 、 0.00281$ $\mathrm{t} /$ 月. 通过估算底泥重金属增量来评价大气沉降对湖泊重金属的贡献表明,大气 $\mathrm{Hg} 、 \mathrm{Zn} 、 \mathrm{~Pb} 、 \mathrm{Cu} 、 \mathrm{As} 、 \mathrm{Cd} 、 \mathrm{Cr}$ 等重金属沉降 对湖泊贡献率分别为 $46.4 \% 、 44.7 \% 、 14.1 \% 、 12.0 \% 、 8.48 \% 、 4.75 \% 、 4.03 \%$.
\end{abstract}

关键词: 大气沉降; 重金属; 入湖通量;乌梁素海

\section{Atmospheric deposition characteristics and fluxes of heavy metals in Lake Ulansuhai}

\author{
YIN Linlin ${ }^{1,2}$, JIA Keli ${ }^{1}$, SHI Xiaohong ${ }^{1}$, ZHAO Shengnan $^{1}$, YANG Fang $^{1} \&$ WU Yong $^{1}$ \\ (1: Inner Mongolia Agricultural University, Hohhot 010018 , P. R. China) \\ (2: Inner Mongolia Soil and Water Conservation Monitoring Station, Huhhot 010019, P. R. China)
}

Abstract: This paper studied heavy metal pollution of the Lake Ulansuhai caused by atmospheric deposition. Atmospheric deposition samples using a wetting method were collected in 1-30 July, 2013 around the lake. The monthly deposition flux and the heavy metal elements of $\mathrm{Cu}, \mathrm{Zn}, \mathrm{Pb}, \mathrm{Cd}, \mathrm{Cr}, \mathrm{Hg}$ and $\mathrm{As}$ deposition to the lake were measured. The element deposition flux ranked in $\mathrm{Zn}>\mathrm{Pb}>\mathrm{Cu}>\mathrm{Cr}>\mathrm{As}>\mathrm{Hg}>\mathrm{Cd}$. The Lake Ulansuhai social investigation and data analysis showed that a larger deposition flux was distributed under the main wind direction as the heavy metals absorbed on the atmospheric particles moved and deposited relying on the wind. Wind is one of the factors affecting the Take Ulansuhai atmospheric heavy metals deposition flux. Besides the large heavy metal amount entering into the lake in the way of draining, the atmospheric deposition was another important pollution sources. The monthly atmospheric deposition amount of $\mathrm{Zn}, \mathrm{Pb}, \mathrm{Cu}, \mathrm{Cr}, \mathrm{As}, \mathrm{Hg}$ and $\mathrm{Cd}$ into the lake were 10.6, 1.04, $1.02,0.833,0.342,0.00514$ and $0.00281 \mathrm{t} /$ month. The heavy metal pollution contribution by the atmospheric deposition was estimated by the increment of heavy metals in the sediments. The atmospheric deposition contribution of $\mathrm{Hg}, \mathrm{Zn}, \mathrm{Pb}, \mathrm{Cu}, \mathrm{As}, \mathrm{Cd}$ and $\mathrm{Cr}$ are estimated with $46.4 \%, 44.7 \%, 14.1 \%, 12.0 \%, 8.48 \%, 4.75 \%$ and $4.03 \%$, respectively.

Keywords: Atmospheric deposition; heavy metal elements; in to-lake fluxes; Lake Ulansuhai

重金属元素通过大气介质传递进人另一介质是其在生态系统循环中不可忽视的一部分. 随着工业、交 通业的迅猛发展, 人类活动导致的大气重金属含量增长显著 ${ }^{[1-2]}$. 大气微粒表面会吸附重金属元素, 携带并 迁移一段距离, 最终通过重力和直接碰撞的干沉降及湿沉降形式进人湖泊, 对湖泊水质产生影响并危及人

* 国家自然科学基金项目 $(51169011,51339002,51169017,51069007,51269016,51269017)$ 、国际合作项目 (2011DFA90710) 和内蒙古自治区科技重大专项项目联合资助. 2013-11-22 收稿; 2014-03-06 收修改稿. 尹琳 琳(1990 ), 女, 硕士研究生;E-mail:yinlinlinimau@ 163. com.

** 通信作者;E-mail:kelijia58@ 126. com. 
类健康 ${ }^{[3-5]}$. 目前乌梁素海重金属的相关研究主要集中在湖泊水体、沉积物的重金属污染空间分布及来源的 分析, 有关乌梁素海水体重金属来源的研究普遍认为河流径流和地表径流及沉积物的释放是湖泊水体重金 属的主要来源, 实际上大气沉降也可能成为乌梁素海水体重金属日益重要的来源, 但目前这一来源普遍被 人们忽视. 大气重金属沉降研究区域目前主要集中在河流、海洋及城市, Kubilay 等 ${ }^{[6]}$ 对 Black Sea 大气沉降 的研究表明, 大气 $\mathrm{Pb}$ 沉降占 $\mathrm{Pb}$ 元素人河量的 $39 \%$. 战雯静等 ${ }^{[7]}$ 研究表明, 长江口大气干沉降总 $\mathrm{Cu}$ 约占水 体中总 $\mathrm{Cu}$ 浓度的 $25 \%$ 左右, 大气沉降对重金属元素向河流输送起着重要作用. 秦晓光等 ${ }^{[8]}$ 研究表明, 东海 每年 $\mathrm{Cu} 、 \mathrm{~Pb} 、 \mathrm{Zn} 、 \mathrm{Cd}$ 大气干沉降总量为 $2376 \mathrm{t}$, 约为长江重金属年人海通量的 $13 \%$, 大气输人是重金属进人 东海的重要途径之一.

上述研究表明, 污染元素通过沉降的方式输人水体, 是湖泊、海洋等水体环境污染的重要来源之一. 目 前国内湖泊的大气重金属沉降研究方面, 仅罗军等报道了太湖大气 $\mathrm{Cu} 、 \mathrm{~Pb}$ 和 $\mathrm{Cd}$ 元素沉降人湖量分别占其 元素总输人量的 $30.5 \% 、 5.9 \%$ 和 $42.5 \%{ }^{[9]}$. 而大气重金属沉降在蒙新高原湖区、云贵高原湖区、青藏高原湖 区、东北平原及山地湖区的研究尚较少, 未引起足够重视. 本文选取的研究区乌梁素海属于蒙新高原湖区, 地处寒旱区典型气候条件和农牧交错区典型下垫面条件, 流域内气候干旱、植被稀疏、沙化严重、沙尘天气 多发,特殊的气候条件为大气重金属沉降提供了有利的条件. 湖泊所处地区巴彦淖尔市是内蒙古自治区西 部新兴的工业城市, 同时也是自治区矿产资源较为丰富的地区之一, 经济的高速发展在为地方经济做出重 要贡献的同时也加剧了流域内乌梁素海水环境重金属污染. 本研究于 2013 年 7 月围绕乌梁素海布设 9 个采 样点进行连续观测, 对大气沉降样品进行了采集, 选取 $\mathrm{Cu} 、 \mathrm{Zn} 、 \mathrm{~Pb} 、 \mathrm{Cd} 、 \mathrm{Cr} 、 \mathrm{Hg} 、 \mathrm{As} 7$ 种重金属元素作为研究对 象, 分析元素含量并探讨其沉降通量及人湖分布特征, 以期考察大气重金属对乌梁素海重金属污染的贡献.

\section{1 材料与方法}

\section{1 研究区概况}

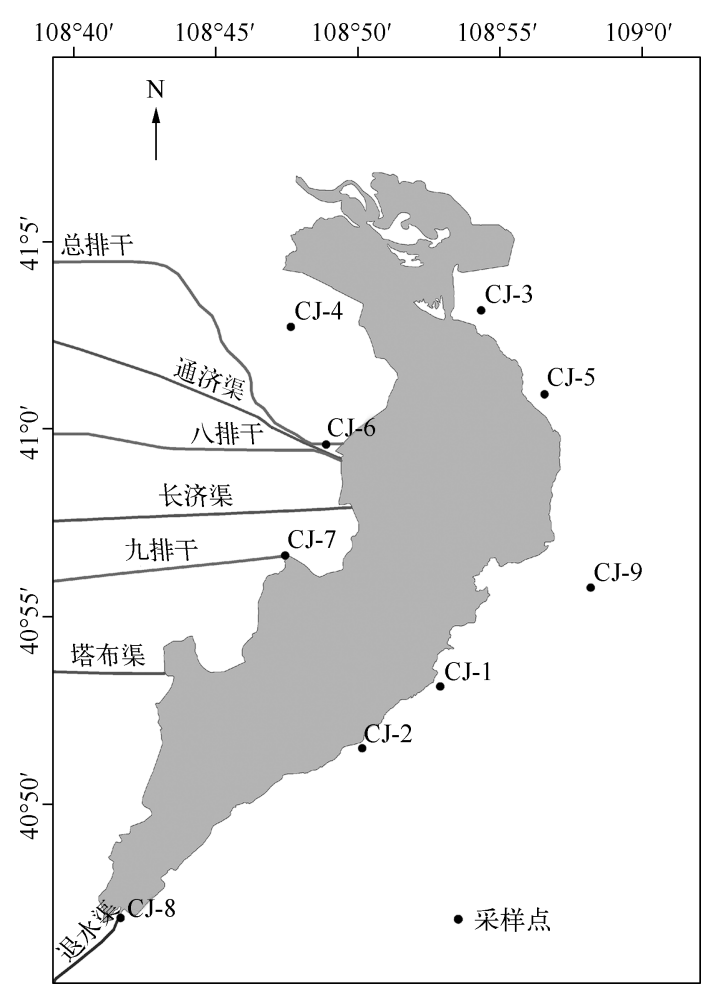

图 1 乌梁素海大气重金属沉降样品采样点布设

Fig. 1 Sampling sites of atmospheric heavy metal elements deposited in Lake Ulansuhai
乌梁素海 $\left(40^{\circ} 36^{\prime} \sim 41^{\circ} 03^{\prime} \mathrm{N}, 108^{\circ} 43^{\prime} \sim\right.$ $108^{\circ} 57^{\prime} \mathrm{E}$ ) 位于内蒙古巴彦淖尔市乌拉特前旗境 内,位于我国北方干旱半干旱地区,属于蒙新高原 湖区. 现有水域面积 $282.17 \mathrm{~km}^{2}$, 其中芦苇区面积 $118.97 \mathrm{~km}^{2}$, 明水区面积 $111.13 \mathrm{~km}^{2}$, 湖面高程多 年平均值为 $1019 \mathrm{~m}, 85 \%$ 水域水深为 $0.8 \sim 1.0 \mathrm{~m}$, 最大水深 $2.5 \mathrm{~m}$ 左右. 湖泊所在地区四季更替明 显, 气温变化差异大, 多年平均气温为 $7.3^{\circ} \mathrm{C}$, 湖水 于每年 11 月初结冰, 直到翌年 3 月末到 4 月初开 始融化, 冰封期约为 5 个月. 全年日照时数为 $3185.5 \mathrm{~h}$, 多年平均降雨量为 $224 \mathrm{~mm}$, 蒸发量为 $1502 \mathrm{~mm}$. 太阳辐射强、降雨稀少、蒸发强烈、干湿 期差异大, 并且经常出现大风和多风天气, 蒸发和 风力对湖泊水环境会产生一定的影响 ${ }^{[10]}$.

\section{2 样品采集}

采用被动采样方式围绕湖区布设点位, 共选 取 9 个大气沉降采样点 (图 1). 因在湖中布设采样 点易受旅游业和捕捞业干扰, 布设于湖边因有芦 苇遮挡, 影响自然沉降量, 且存在一定的固定难 度,所以此方法未被采纳。

为尽量准确地观测并收集大气沉降物质以估 算分析其人湖情况, 选取采样点时应遵循以下原 则: (1) 避开烟图和交通要道等点、线污染源的局部 
污染; (2) 放置于村民屋顶 (一般高度在 3 4 m) , 避免受到地面扬尘及人为干扰; (3) 采用湿法收集, 避免沉降 物的反复扬起; (4) 采样点四周 $(25 \mathrm{~m} \times 25 \mathrm{~m})$ 无高大树木和建筑遮挡.

样品采用无盖聚乙烯桶 (内壁光滑, 接收口内径为 $27.5 \mathrm{~cm}$, 高为 $40 \mathrm{~cm}$ ) 收集, 取样器外围垒放砖块加以 固定. 每个采样点放置 4 个相同的采样器, 采用湿法收集, 根据历年 7 月蒸发量在桶内装人高约 $20 \mathrm{~cm}$ 的超 纯水, 保证采样器内在实验期间始终有适量体积的溶液覆盖底部, 采样时间为 2013 年 7 月 1 日-30日,为期 $30 \mathrm{~d}$. 采样容器内样品装人广口瓶带回实验室, 用不锈钢铌子将落人缸内的树叶、昆虫等异物取出, 静置 $3 \mathrm{~d}$, 用虹吸法分离上清液并记录体积, 下层悬浊液和沉淀物用 $0.45 \mu \mathrm{m}$ 的聚酯纤维滤膜过滤, 记录滤液体积, 滤 液与虹吸取得的上清液混合即为样品元素溶解部分; 下层悬浊液及沉淀物用真空泵进行固液分离, 抽取在 滤膜上的沉淀物在 $65^{\circ} \mathrm{C}$ 下恒温烘干, 烘至沉淀物与滤膜分离的状态, 用刀片刮取至滤膜上无残留, 沉淀物研 磨后过 $0.5 \mathrm{~mm}$ 篎,过滤小树枝等异物. 上述所有样瓶及器材在使用前均经过 $10 \% \mathrm{HCl}$ 溶液浸泡 $24 \mathrm{~h}$ 、蒸馏 水冲洗、超纯水润洗及晾干处理.

\section{3 样品分析}

因本研究采用湿法收集沉降样品, 野外放置收集样品过程中沉淀部分的重金属元素会溶解并向水中释 放, 因此样品被分为溶解部分 (溶液) 和沉淀部分 (沉淀物), 溶解部分和沉淀部分均测试 $\mathrm{Cu} 、 \mathrm{Zn} 、 \mathrm{~Pb} 、 \mathrm{Cd} 、 \mathrm{Cr} 、$ $\mathrm{Hg} 、 \mathrm{As} 7$ 种元素含量. 因沉淀部分检测的是滤膜上刮取的固体物质, 滤膜孔隙内可能残留细小微粒, 故根据 检测数值估算的结果可能略低估了重金属人湖通量.

沉淀物样品 $\mathrm{Cu} 、 \mathrm{Zn} 、 \mathrm{~Pb} 、 \mathrm{Cd} 、 \mathrm{Cr}$ 元素采用原子吸收分光光谱法测试, 检测依据 $\mathrm{GB} / \mathrm{T} 17141-1997 ; \mathrm{Hg}$ 和 As 元素采用原子苂光光谱法测试, Hg 元素检测依据 NY/T 1121.10-2006, As 元素检测依据 NY/T 1121.112006. 溶解部分样品 $\mathrm{Cu} 、 \mathrm{Zn} 、 \mathrm{~Pb} 、 \mathrm{Cd} 、 \mathrm{Cr}$ 元素采用原子吸收分光光谱法测试, 检测依据 $\mathrm{GB} / \mathrm{T} 5084-2005 ; \mathrm{Hg}$ 和 As 元素采用原子苂光光谱法测试, Hg 元素检测依据 HJ597-2001; As 元素检测依据《水和废水监测分析 方法》 ${ }^{[11]}$. 溶液样品的检出限: $\mathrm{Cu} 、 \mathrm{Zn} 、 \mathrm{~Pb}$ 均为 $0.005 \mu \mathrm{g} / \mathrm{L}, \mathrm{Cr}$ 为 $0.02 \mu \mathrm{g} / \mathrm{L}, \mathrm{Cd}$ 为 $0.01 \mu \mathrm{g} / \mathrm{L}, \mathrm{Hg}$ 为 $0.05 \mu \mathrm{g} / \mathrm{L}, \mathrm{As}$ 为 $0.01 \mu \mathrm{g} / \mathrm{L}$; 沉淀物样品的检出限: $\mathrm{Cu} 、 \mathrm{Zn} 、 \mathrm{~Pb}$ 均为 $0.005 \mu \mathrm{g} / \mathrm{kg}, \mathrm{Cr}$ 为 $0.02 \mu \mathrm{g} / \mathrm{kg}, \mathrm{Cd}$ 为 $0.01 \mu \mathrm{g} / \mathrm{kg}, \mathrm{Hg}$ 为 $0.05 \mu \mathrm{g} / \mathrm{kg}$, As 为 $0.01 \mu \mathrm{g} / \mathrm{kg}$.

本文采用 Excel 2003 对原始数据进行描述性统计分析,图形采用 ArcGIS 10.0 软件绘制.

\section{4 沉降通量计算}

根据分析测试获得溶解部分元素的浓度和沉淀部分元素的质量分数, 可计算各采样点某元素的沉 降量:

$$
Q_{\mathrm{t}}=Q_{\mathrm{s}}+Q_{\mathrm{i}}=V \times C_{\mathrm{s}}+M \times C_{\mathrm{i}}
$$

式中, $Q_{\mathrm{t}}$ 为总沉降量 $(\mathrm{mg} /$ 月 $), Q_{\mathrm{s}}$ 为溶解部分沉降量 $(\mathrm{mg} /$ 月 $), Q_{\mathrm{i}}$ 为沉淀部分沉降量 $(\mathrm{mg} /$ 月 $), V$ 为溶液总 体积 $(\mathrm{L}), C_{\mathrm{s}}$ 为溶解样品元素浓度 $(\mu \mathrm{g} / \mathrm{L}), M$ 为沉淀物总量 $(\mathrm{g} /$ 月 $), C_{\mathrm{i}}$ 为沉淀样品元素质量分数 $(\mathrm{mg} / \mathrm{kg})$.

根据上述沉降量的计算结果可获得该采样点某元素的沉降通量：

$$
F=Q_{\mathrm{t}} / S=F_{\mathrm{s}}+F_{\mathrm{i}}=Q_{\mathrm{s}} / S+Q_{\mathrm{i}} / S
$$

式中, $F$ 为沉降通量 $\left(\mathrm{mg} /\left(\mathrm{m}^{2} \cdot\right.\right.$ 月 $\left.)\right), S$ 为采样面积 $\left(\mathrm{m}^{2}\right), F_{\mathrm{s}}$ 为可溶部分沉降通量 $\left(\mathrm{mg} /\left(\mathrm{m}^{2} \cdot\right.\right.$ 月 $\left.)\right), F_{\mathrm{i}}$ 为不 溶部分沉降通量 $\left(\mathrm{mg} /\left(\mathrm{m}^{2} \cdot\right.\right.$ 月 $\left.)\right)$.

采样器面积的计算如下:

$$
S=3.14 \times D^{2} /(4 \times 1000) \times N
$$

式中, $D$ 为采样器的直径 $(\mathrm{cm}), N$ 为某采样点放置的用于重金属分析采样的采样器个数. 本研究采样器内径 为 $27.5 \mathrm{~cm}$, 每个采样点放置 4 个采样桶, 根据上述公式可计算出每个采样点收集面积为 $0.2375 \mathrm{~m}^{2}$.

\section{2 结果与分析}

\section{1 元素溶解部分与沉淀部分通量}

采集的大气重金属沉降样品中元素绝大部分以不溶解的沉淀状态存在,其中以 $\mathrm{Cr}$ 元素最为明显,沉淀 
部分与溶解部分比值高达 323 (图 2). 这是因为水环境中 $\mathrm{Cr}$ 主要以 $\mathrm{Cr}^{3+}$ 难溶性氧化物存在于沉积物中, 大 部分 $\mathrm{Cr}$ 易于被沉积物吸附, 不易向水体迁移 ${ }^{[12]} ; \mathrm{Pb}$ 元素次之, 但比值也高达 64 , 因为 $\mathrm{Pb}$ 主要以 $\mathrm{Pb}(\mathrm{OH})_{2}$ 和 $\mathrm{PbCO}_{3}$ 的沉淀形式存在于沉积物中 ${ }^{[13]} ; \mathrm{Hg}$ 元素比值最小, 为 $5, \mathrm{Hg}$ 离子向水中的释放量最大, 大气中 $\mathrm{Hg}$ 的 存在形态主要是 $\mathrm{Hg}^{0}, \mathrm{Hg}^{0}$ 易被空气中 $\mathrm{O}_{3}$ 等强氧化剂氧化为 $\mathrm{Hg}^{2}{ }^{2}[14]$, 而可溶性 $\mathrm{Hg}^{2+}$ 通过雨水冲刷和干沉降 进人水体, 因而增加了 $\mathrm{Hg}$ 在溶液部分的含量; $\mathrm{Cd}$ 元素的水中溶解量仅次于 $\mathrm{Hg}$ 元素, 主要是由于水溶性 $\mathrm{Cd}$ 的溶解度随氧化还原电位增大而增大, 在氧化还原电位较低时, 易生成沉淀, 夏季氧化还原电位较高, 不易 生成沉淀, 易向水中迁移 ${ }^{[15]}$. 其他元素沉淀部分与溶解部分比值介于 $10 \sim 100$ 之间. Zn 元素沉淀部分与溶 解部分通量值均为最大值, 沉淀部分各重金属元素通量均值大小为: $\mathrm{Zn}>\mathrm{Pb}>\mathrm{Cu}>\mathrm{Cr}>\mathrm{As}>\mathrm{Hg}>\mathrm{Cd}$, 与采 样点元素质量分数均值变化规律相同. 溶解部分各重金属元素间通量均值大小为: $\mathrm{Zn}>\mathrm{As}>\mathrm{Cu}>\mathrm{Pb}>\mathrm{Cr}>$ $\mathrm{Hg}>\mathrm{Cd}$, 与采样点元素浓度均值变化规律相同.

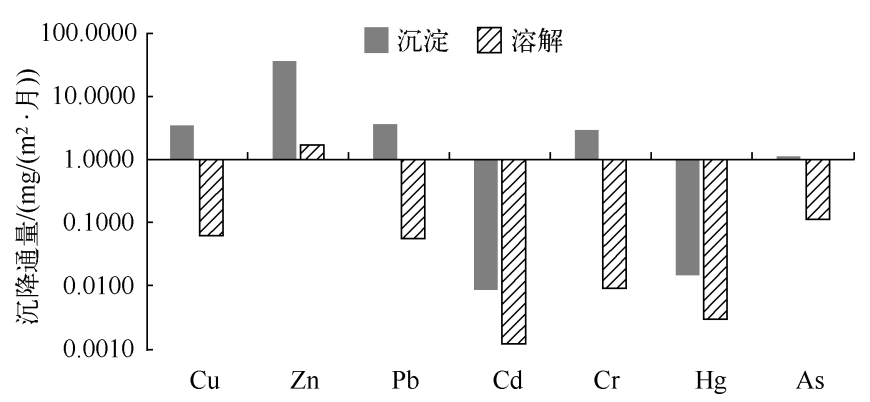

图 2 乌梁素海重金属沉降样品的沉淀部分与溶解部分元素通量

Fig. 2 Comparison of the soluble and insoluble fractions of heavy metal elements deposited in Lake Ulansuhai

\section{2 元素沉降通量水平及不同研究区对比}

从各重金属元素间沉降通量比较可以看出, Zn 元素沉降通量明显高于其他元素, 各采样点沉降通量均 值可达 $37.6 \mathrm{mg} /\left(\mathrm{m}^{2} \cdot\right.$ 月), 高出 $\mathrm{Cu} 、 \mathrm{~Pb} 、 \mathrm{Cr}$ 元素 10 余倍, 高出 $\mathrm{As}$ 元素 30 余倍, 高出 $\mathrm{Hg}$ 元素 3 个数量级, 高 出 $\mathrm{Cd}$ 元素 4 个数量级. $\mathrm{Cd}$ 元素沉降通量最低, 采样点均值仅为 $0.00971 \mathrm{mg} /\left(\mathrm{m}^{2} \cdot\right.$ 月). 元素沉降通量最大值 与最小值差异的比较发现, 各元素沉降通量的最值差异均很大, 其中 $\mathrm{Cr}$ 元素的差异性最大, 相差 60 余倍, 所以 $\mathrm{Cr}$ 元素沉降通量的空间变化最大; Hg 元素沉降通量的最值差异较小, 相差 6.8 倍, Hg 元素沉降通量的空间变 化最小 (表 1).

表 1 乌梁素海大气重金属各元素沉降通量

Tab. 1 Flux of each heavy metal element from the atmospheric deposition in Lake Ulansuhai

\begin{tabular}{rlllllll}
\hline \multirow{2}{*}{ 统计量 } & \multicolumn{7}{c}{ 沉降通量 $/\left(\mathrm{mg} /\left(\mathrm{m}^{2} \cdot\right.\right.$ 月 $\left.)\right)$} \\
\cline { 2 - 9 } & $\mathrm{Cu}$ & $\mathrm{Zn}$ & $\mathrm{Pb}$ & $\mathrm{Cd}$ & $\mathrm{Cr}$ & $\mathrm{Hg}$ & $\mathrm{As}$ \\
\hline 最大值 & 7.60 & 65.4 & 7.40 & 0.0250 & 6.38 & 0.0300 & 2.64 \\
最小值 & 0.400 & 10.6 & 0.180 & 0.00222 & 0.103 & 0.00441 & 0.0771 \\
平均值 & 3.54 & 37.6 & 3.59 & 0.00971 & 2.95 & 0.0180 & 1.19 \\
标准差 & 2.88 & 24.3 & 3.06 & 0.00851 & 2.70 & 0.0121 & 1.08 \\
\hline
\end{tabular}

乌梁素海 Cd 元素大气沉降通量明显低于其他研究区, 低于太湖近 3 个数量级, 但其他元素通量水平均 高于北美湖区, 其中以 $\mathrm{Zn} 、 \mathrm{Cr}$ 元素最为显著, 高出 Erie 湖数十倍, 高于其他两个北美湖区 2 个数量级. 乌梁 素海重金属沉降通量与太湖重金属沉降通量比较发现, 除 Cd 元素外,其他元素沉降通量与太湖相应元素沉 降通量在同一数量级, 且 $\mathrm{Cr} 、 \mathrm{~Pb}$ 元素沉降通量高于太湖 (表 2). 本研究重金属沉降通量为 7 月份元素沉降通 量监测值, 与其他研究区的沉降通量月平均值相比较可能存在略微偏差, 但研究区整体较高的沉降通量水 
平说明乌梁素海大气重金属污染对湖泊水环境已经存在一定程度的影响.

表 2 乌梁素海与其他湖泊大气重金属月沉降通量对比 *

Tab. 2 Comparison of atmospheric deposition fluxes of heavy metal between Lake Ulansuhai and other lakes

\begin{tabular}{|c|c|c|c|c|c|c|c|}
\hline \multirow{2}{*}{ 湖泊 } & \multicolumn{7}{|c|}{ 沉降通量 $/\left(\mathrm{mg} /\left(\mathrm{m}^{2} \cdot\right.\right.$ 月 $\left.)\right)$} \\
\hline & $\mathrm{Cu}$ & $\mathrm{Zn}$ & $\mathrm{Pb}$ & $\mathrm{Cd}$ & $\mathrm{Cr}$ & $\mathrm{Hg}$ & As \\
\hline 乌梁素海 & 3.54 & 37.6 & 3.59 & 0.00971 & 2.95 & 0.0180 & 1.19 \\
\hline 太湖 ${ }^{[9]}$ & 12.1 & 87.5 & 3.17 & 0.580 & 1.67 & - & - \\
\hline Erie 湖 ${ }^{[16]}$ & 0.350 & 1.38 & 0.150 & 0.0410 & 0.0890 & - & - \\
\hline Michigan 湖 ${ }^{[16]}$ & 1.56 & 0.500 & 0.130 & 0.0380 & 0.0170 & - & - \\
\hline Superior 湖 $[16]$ & 0.260 & 0.730 & 0.120 & 0.0380 & 0.0170 & - & - \\
\hline
\end{tabular}

* “-”代表无检测数据;其他研究区元素沉降通量均为月均沉降通量值.

\section{3 元素沉降通量空间分布}

重金属沉降通量空间分布差异较大,采样 点 CJ-1、CJ-2、CJ-6 和 CJ-7 的沉降通量明显高 于其他采样点,湖泊的西南区域沉降通量较大 (图 3). 通过对各采样点的社会情况调查, 采样 点 CJ-6 处于农牧交错下垫面条件,且周围村落 居民人口数目较大, 总耕地面积及畜牧业发展 水平均处于较高水平, 采样点 $\mathrm{CJ}-2$ 和 CJ-7地处 畜牧业发达地区, 居民人口数目较小但人均养 殖牲畜量显著高于其他点位, 采样点 CJ-1 所处 地区渔业发达,该村落大部分村民以渔业为生, 是乌梁素海所处地区较少的渔业高产村落. 耕 地施用的化肥、牲畜的粪便及渔业捕捞等面源 污染源产生的重金属,一部分会分解挥发释放 在大气中并吸附于微粒进行迁移, 这是导致其 通量水平高于其他点位的主要原因之一. 采样 点 CJ-4 和 CJ-6 的元素通量值大小差异较大,元 素含量近乎相同,但收集的沉淀物质量差异较 大, 分别为 2.08 和 $64.63 \mathrm{~g}$, 说明沉降通量除了 与元素含量高低有关外, 还与大气沉降总量 有关.

大气微量金属含量的变化规律除了受其来 源的源强影响之外还与盛行风向、风况等气象 条件有关 ${ }^{[17-19]}$, Rojas 等对 de la Plata 河的大气 氮沉降研究表明,沉降通量高值出现在主风向 的下风向处,大气沉降通量与风向有关 ${ }^{[20]}$. 乌 梁素海上游 $50 \mathrm{~km}$ 内没有诸如化工厂和造纸厂

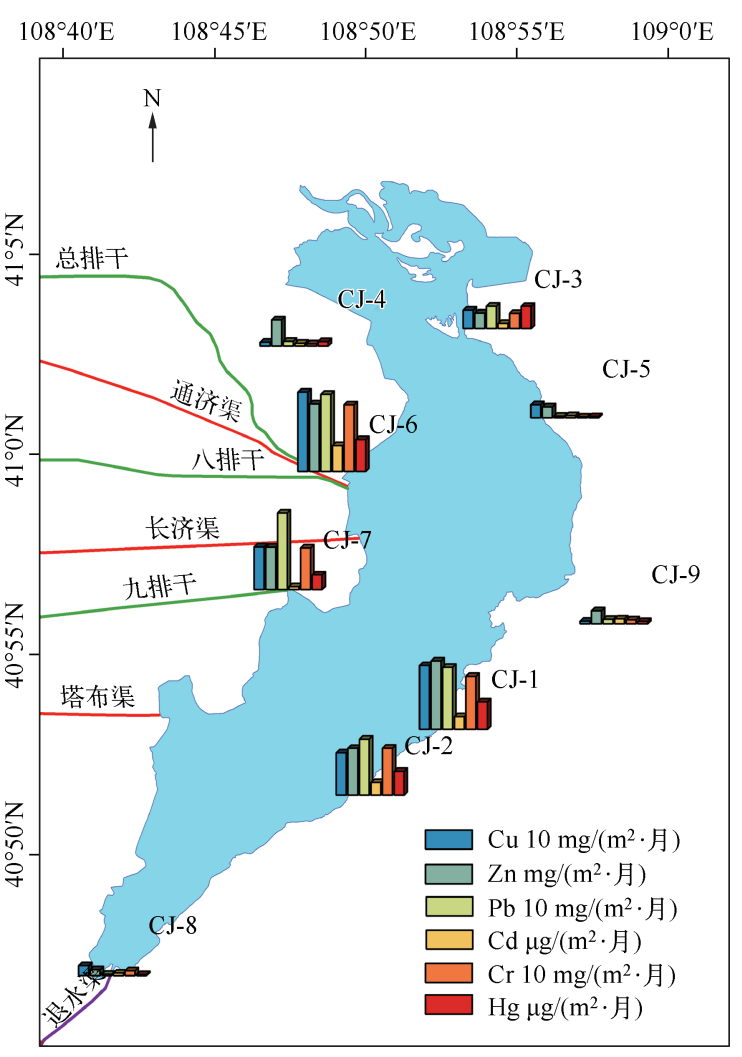

图 3 乌梁素海大气沉降重金属元素通量空间分布

Fig. 3 Distribution of atmospheric deposition flux of heavy metal in Lake Ulansuhai 等点源污染源, 距离市区较远, 多年主风向为北 偏东北方向, 流域内气候干旱, 植被稀疏, 大风及沙尘天气频发, 重金属元素吸附于大气微粒, 主要依靠风 力、风向等气象条件进行迁移,故风向是湖泊大气重金属元素沉降的可能影响因素之一. 因此本文根据乌梁 素海多年 7 月份风向数据, 结合乌梁素海大气重金属沉降通量分析其相关性.

通过对 2006-2010 年 7 月份风向数据收集统计,归纳 16 个方向的风向频率,绘制风向玫瑰图. 统计结 


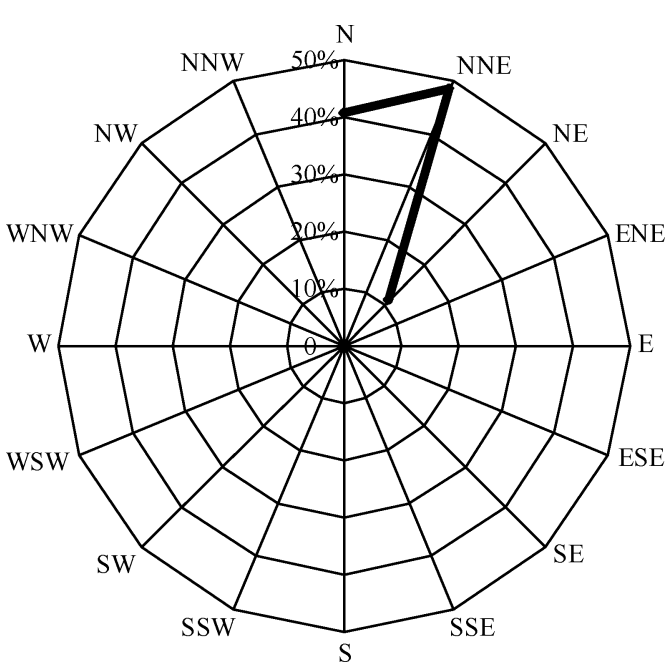

图 4 乌梁素海 2006-2010 年 7 月风向玫瑰图

Fig. 4 Wind rose (direction wind is blowing from) of July for year 2006-2010 in Lake Ulansuhai
果显示每年有 $99.3 \%$ 的时间风向会从北至东北 $(\mathrm{N} \rightarrow \mathrm{NE}$ ) 方向吹向湖泊西南方向 (图 4). 重金属元 素在西南区域采样点 CJ-1、CJ-2、CJ-6 和 CJ-7 的沉降 通量均高于其他点位, 即乌梁素海较大的沉降通量 值主要出现在湖泊南 $\rightarrow$ 西北 $(\mathrm{S} \rightarrow \mathrm{NW})$ 的扇形区域, 这是由于风频出现在北 $\rightarrow$ 东北的扇形区, 大气微粒 携带重金属元素随风力迁移并沉降在下风向处, 这 说明风向也是影响乌梁素海大气重金属沉降通量水 平的主要影响因素之一. 故风向和湖泊周围面源污 染强度的共同作用是影响乌梁素海重金属通量水平 的主要因素.

\section{3 大气重金属沉降对湖泊重金属的贡献}

乌梁素海是河套农业灌区农田灌溉退水的唯一 受纳水体和排水通道, 是当地农田退水、工业废水和 生活污水的唯一承泄渠道, 每年大约有 $5 \times 10^{8} \mathrm{~m}^{3}$ 的 农田退水、 $2 \times 10^{8} \mathrm{~m}^{3}$ 的工业废水和生活污水主要通 过各支渠和小排干汇人总排干沟及八排干沟、九排 干沟, 其中近 $90 \%$ 的污废水经总排干排人乌梁素

海, 排放的污废水携带如 $\mathrm{Pb} 、 \mathrm{Hg} 、 \mathrm{As} 、 \mathrm{Cd} 、 \mathrm{Cr}$ 等重金属 ${ }^{[21-23]}$, 因此排干输人为乌梁素海重金属污染的重要来 源. 除排干输人方式, 重金属也可通过化石燃料燃烧、汽车尾气、烟气、粉尘和风沙等进人大气, 吸附在大气 微粒上, 最终通过大气沉降的方式进人乌梁素海, 因此, 对不同污染源输人的重金属沉降通量及人湖量进行 比较以评价大气沉降对乌梁素海重金属污染的贡献.

根据 2009 年 TM 卫星遥感图像显示, 乌梁素海现有水域面积 $282.17 \mathrm{~km}^{2}$, 基于此水域面积和大气重金 属沉降通量检测数据, 估算乌梁素海 7 月大气沉降输人湖泊重金属的总量. 根据乌梁素海 2013 年 7 月总排 干沟、八排干沟和九排干沟的排水量收集资料及人湖口处湖水重金属实测浓度对排干输人方式人湖量进行 估算,进而评价大气沉降对乌梁素海重金属的影响.

由表 3 可以看出, 通过排干输人乌梁素海的 7 种重金属元素中, Zn 元素人湖量与大气沉降通量相似,仍 存在较高的输人量, 且明显高于其他元素, $\mathrm{Cu} 、 \mathrm{As}$ 元素也呈现出较高的输人量. $\mathrm{Cd}$ 元素排干输人量最低, 仅 为 $0.000741 \mathrm{t} /$ 月, 这是因为 $\mathrm{Cd}$ 排人水体以后, 可被水体中的底泥、腐殖质和悬浮物等颗粒物所吸附, 而且还 受胶体颗粒物对镉化物的吸附作用、水体的氧化还原电位等因素的影响. $\mathrm{Cd}$ 的大气沉降人湖量明显高于排 干输人量, 说明大气沉降方式是水体中 $\mathrm{Cd}$ 元素获取的重要途径. 不同输人方式下重金属人湖量的对比说明 大气沉降是乌梁素海水体重金属的另一重要污染源.

表 3 通过大气沉降与排干输人乌梁素海的重金属沉降通量及人湖量对比

Tab. 3 Comparison of flux and amount of heavy metal to Lake Ulansuhai from atmospheric deposition and drainage

\begin{tabular}{cccccccc}
\hline 指标 & $\mathrm{Cu}$ & $\mathrm{Zn}$ & $\mathrm{Pb}$ & $\mathrm{Cd}$ & $\mathrm{Cr}$ & $\mathrm{Hg}$ & $\mathrm{As}$ \\
\hline 大气沉降月通量 $/\left(\mathrm{mg} /\left(\mathrm{m}^{2} \cdot\right.\right.$ 月 $\left.)\right)$ & 3.54 & 37.6 & 3.59 & 0.00971 & 2.95 & 0.0180 & 1.19 \\
大气沉降月入湖量/(t/月) & 1.02 & 10.6 & 1.04 & 0.00281 & 0.833 & 0.00514 & 0.342 \\
排干月入湖量/(t/月 $)$ & 0.362 & 2.91 & 0.114 & 0.000741 & - & 0.102 & 0.604 \\
\hline
\end{tabular}

经污染源排人乌梁素海的重金属, 经过迁移转化主要沉积富集于湖泊底泥. 本文根据已有的乌梁素海 底泥重金属含量数据 ${ }^{[24]}$, 估算底泥重金属增量, 以评价大气沉降对湖泊重金属的贡献. 近 40 年来, 乌梁素海 蓄积的沉积淤泥总体积约为 $1.08 \times 10^{8} \mathrm{~m}^{3}$, 沉积速率为 $6 \sim 9 \mathrm{~mm} / \mathrm{a}^{[25-26]}$, 平均每年蓄积量约为 $4.19 \times$ $10^{6} \mathrm{t}^{[27]}$. 根据底泥重金属含量及底泥蓄积量, 获得湖泊底泥中重金属的增量. 
由表 4 可以看出, 乌梁素海底泥中 $\mathrm{Zn}$ 元素月平均增量最高, $\mathrm{Cr}$ 元素次之, $\mathrm{Hg}$ 元素的增量仅为 $0.0113 \mathrm{t} /$ 月. $\mathrm{Cd}$ 元素的月平均增量虽然较少, 但其大气沉降和排干输人所占比重均很小, 说明除大气沉降和 排干输人方式外, 底泥中元素的释放等内源污染也是湖泊中获取 $\mathrm{Cd}$ 元素的重要途径. 虽然 $\mathrm{Hg}$ 元素的月总 人湖量很少, 但是其大气沉降贡献率高达 $46.4 \%$, 说明大气沉降是乌梁素海 $\mathrm{Hg}$ 元素的重要来源. Zn 元素的 大气沉降输人量对湖泊的贡献仅次于 $\mathrm{Hg}$ 元素, 且其底泥中的月平均增量及大气沉降月人湖量均很高, 说明 乌梁素海 Zn 元素的富集量很高且大气沉降方式是重要的输人来源. 太湖重金属 $\mathrm{Cu} 、 \mathrm{Cd}$ 元素大气沉降月人 湖量分别占其元素月总输人量的 $30.5 \%$ 和 $42.5 \%{ }^{[9]}$, 与太湖不同, 乌梁素海大气 $\mathrm{Cu} 、 \mathrm{Cd}$ 元素沉降的贡献率 相对较低, 而 $\mathrm{Zn} 、 \mathrm{Hg}$ 元素呈现出很高的贡献率, 但大气重金属沉降对乌梁素海整体呈现较高的贡献率, 说明 大气沉降是乌梁素海重金属不可忽视的重要来源, 在湖泊水质及重金属污染源等研究中应引起关注.

表 4 大气重金属沉降对乌梁素海重金属的贡献率

Tab. 4 Contribution of atmospheric heavy metal deposition in Lake Ulansuhai

\begin{tabular}{lccccccc}
\hline 指标 & $\mathrm{Cu}$ & $\mathrm{Zn}$ & $\mathrm{Pb}$ & $\mathrm{Cd}$ & $\mathrm{Cr}$ & $\mathrm{Hg}$ & $\mathrm{As}$ \\
\hline 底泥重金属含量 $/(\mu \mathrm{g} / \mathrm{g})^{[24]}$ & 23.7 & 67.8 & 20.3 & 0.173 & 58.9 & 0.0304 & 11.5 \\
大气沉降月人湖量 $/(\mathrm{t} /$ 月 $)$ & 1.02 & 10.6 & 1.04 & 0.00281 & 0.833 & 0.00514 & 0.342 \\
底泥重金属月平均增量/(t/月 ) & 8.31 & 23.7 & 7.14 & 0.0590 & 20.6 & 0.0113 & 4.01 \\
大气沉降对湖泊重金属贡献率/\% & 12.0 & 44.7 & 14.1 & 4.75 & 4.03 & 46.4 & 8.48 \\
\hline
\end{tabular}

\section{4 结论}

1) 乌梁素海大气重金属沉降样品中元素绝大部分以不溶解的沉淀状态存在于样品中, $Z n$ 元素在溶解 部分和沉淀部分的通量值均最高, $\mathrm{Hg}$ 元素因其在大气中被氧化后大部分以可溶性的 $\mathrm{Hg}^{2+}$ 进人水体使其在 水体中溶解量最大,而 $\mathrm{Cr}$ 元素因易于被沉物吸附使其在溶液部分含量最小.

2) 大气重金属沉降通量与元素含量水平和大气沉降总量有关.

3) 湖泊周围农业、畜牧业等面源污染源是影响大气重金属沉降通量水平的主要因素之一. 除此之外,根 据风向数据统计分析,乌梁素海风频主要出现在北 $\rightarrow$ 东北的扇形区,大气微粒携带重金属随风迁移并沉降 在主风向的下风向区域,即较大的沉降通量值出现在湖泊西南区域,这说明风向也是影响乌梁素海大气沉 降通量的主要因素之一. 故风向条件及湖泊周围面源污染源强度的共同作用是影响乌梁素海大气沉降通量 水平的主要因素.

4) 对不同输人方式的通量及输人量比较发现,除排干来源外,大气沉降是乌梁素海水体重金属元素的 另一重要污染源.

5) 大气重金属 $\mathrm{Hg} 、 \mathrm{Zn} 、 \mathrm{~Pb} 、 \mathrm{Cu} 、 \mathrm{As} 、 \mathrm{Cd}$ 和 $\mathrm{Cr}$ 沉降对湖泊重金属贡献分别为 $46.4 \% 、 44.7 \% 、 14.1 \%$ 、 $12.0 \% 、 8.48 \% 、 4.75 \%$ 和 $4.03 \%$. 大部分元素均呈现出较高的贡献率, 因此大气重金属沉降是乌梁素海水 体重金属的重要来源之一,在湖泊水质治理及污染源研究方面大气沉降应引起关注.

致谢: 审稿专家对本文的修改提出了许多宝贵建议, 谨致谢忱.

\section{5 参考文献}

[1] 侯佳渝, 刘金成, 曹淑萍等. 天津市城区大气干湿沉降地球化学研究. 地质调查与研究, 2013,36(2): 131-135.

[ 2 ] 刘昌岭, 陈洪涛. 大气中微量元素的沉降对海洋生态系统的影响. 海洋通报,2003,22(2):89-95.

[ 3 ] 汤 洁,李 娜, 李海毅等. 大庆市大气干湿沉降重金属元素通量及来源. 吉林大学学报, 2012,42(2):507-513.

[ 4 ] 邢小茹,薛生国,张乃英等. 鞍山市大气尘和金属元素沉降通量及污染特征. 中国环境监测, 2010,26(2):11-15.

[ 5 ] 杨忠平,卢文喜,龙玉桥. 长春城区重金属大气干湿沉降特征. 环境科学研究, 2009,22 (1) :28-34.

[6] Kubilay N, Yemenicioglu S, Saydam AC. Airborne material collections and their chemical composition over the Black Sea. Marine Pollution Bulletin, 1995, 30(7) : 475-483.

[ 7 ] 战雯静,张 艳,马蔚纯等. 长江口大气重金属污染特征及沉降通量. 中国环境科学, 2012,32 (5):900-905.

[ 8 ] 秦晓光,程祥圣,刘富平. 东海海洋大气颗粒物中重金属的来源及人海通量. 环境科学, 2011,32(8) :2193-2196. 
[9] 罗 军. 大气中氮磷及重金属沉降对太湖水质的影响 [学位论文]. 南京:南京大学,2004.

[10］史小红,李畅游,贾克力.乌梁素海污染现状及驱动因子分析. 环境科学与技术, 2007,4:37-40.

[11] 国家环境保护总局《水和废水监测分析方法》编委会. 水和废水监测分析方法: 第 4 版. 北京: 中国环境科学出版 社, 2002.

[12 ] Lin ZL, Wang R, Wang CM. Study on the distribution of water pollutants in Wuliangsuhai Lake basin. Environmental Pollution and Control, 2011, 33(9):19-24.

[13] 鄢敏林,周圣东,胡淑圆等. 重金属铅污染应急处理技术中试研究. 供水技术,2012,6(2):26-29.

[14] Liu RH, Wang QC, Hao QJ. Distribution character of $\mathrm{Hg}$ in wetland soil in Sanjiang Plain and analysis of influential factors. Journal of Soil Water Conservation, 2003, 17(1) : 122-130.

[15] 张庆辉. 镉环境地球化学特征. 阴山学刊,2005,19(3):31-34.

[16] 吴辰熙, 祁士华, 方 敏等. 福建省泉州湾大气降尘中的重金属元素的沉降特征. 环境科学研究, 2006,19(6): 27-30.

[17] 张远辉,詹建琼,陈立奇等. 台湾海峡大气微量金属的化学特征及其如海通量. 台湾海峡, 2009,28(4):447-454.

[18 ] Gao Y, Arimoto R, Duce RA et al. Temporal and spatial distributions of dust and its deposition to the China Sea. Tellus, 1997, 49B : 172-189.

[19］陈立奇,王志红,杨绪林等. 台湾海峡西部海域大气中金属的特征 I. 金属的浓度和粒度分布. 海洋学报, 1998,20 (6) : 31-37.

[20] Rojas ALP, Venegas LE. Dry and wet deposition of nitrogen emitted in Buenos Aires City to waters of de la Plata river. Water, Air, and Soil Pollution, 2008, 193: 175-188.

[21] 赵胜男.乌梁素海沉积物重金属生物活性及环境污染评估. 生态环境学报,2013,22(3):481-489.

[22] LI X, LI CY. Influence on emerged plant in the process of numerical simulation about lake water quality. Environmental Science, 2010, 31(12) : 2890-2895.

[23] 姜忠峰,李畅游. 乌梁素海进出水量变化及水量平衡初步分析. 人民黄河,2013,35(9):76-78.

[24] 赵锁志. 内蒙古乌梁素海底泥中重金属污染的分布特征. 现代地质,2009,23(1):103-107.

[25] 刘 旭,李畅游,贾克力等.乌梁素海沉积物中营养盐分布特征与固碳能力. 环境化学,2013,32 (6):993-1001.

[26] 朱广伟,陈英旭. 沉积物中有机质的环境行为研究进展. 湖泊科学, 2001,13(3):272-279.

[27] 刘 旭.乌梁素海底泥农田利用可行性分析及其环境风险评价 [学位论文]. 呼和浩特: 内蒙古农业大学,2013. 